\title{
Combined Electrical Resistivity Imaging and Electromagnetic Survey for Groundwater Studies in the Tarkwa Mining Area, Ghana*
}

\author{
${ }^{1}$ J. Seidu ${ }^{1}$ A. Ewusi ${ }^{1}$ J. S. Y. Kuma \\ ${ }^{1}$ University of Mines and Technology (UMaT), Tarkwa
}

Seidu, J., Ewusi, A., and Kuma, J. S. Y. (2019), "Combined Electrical Resistivity Imaging and Electromagnetic Survey for Groundwater Studies in the Tarkwa Mining Area, Ghana”, Ghana Mining Journal, Vol. 19, No. 1, pp. $29-41$.

\begin{abstract}
The major source of potable water in Tarkwa is the Bonsa Treatment Plant sourced from the Bonsa River. The activities of illegal miners along the banks of the Bonsa River has resulted in pollution of the river. This has resulted in high treatment cost and irregular supply of water to the Tarkwa Township and surrounding communities that are fed by the Bonsa Treatment Plant. In view of the difficulty in getting frequent and regular potable supply of water, people have resorted to construction of boreholes and hand-dug wells. However, the success rates and borehole yields are low especially in the hydrogeologically difficult terrains in the Tarkwa area. The aim of this paper is to investigate the hydrogeological conditions of the Tarkwa area using both the Electrical Resistivity Imaging (ERI) and Electromagnetic (EM) geophysical techniques to determine the electrical resistivity and conductivity values that are related to groundwater accumulation, so that potential water-bearing zones can be identified. Results from electrical resistivity show that the general resistivity distribution in the Tarkwa area is between $32 \Omega \mathrm{m}$ and $100000 \Omega \mathrm{m}$. Water-bearing zones in the Huni Sandstone occur to a depth of $35 \mathrm{~m}$ with an average resistivity value of $400 \Omega \mathrm{m}$, at a depth of $60 \mathrm{~m}$ and a resistivity of $600 \Omega \mathrm{m}$ in the Tarkwa Phyllite, at a depth of $55 \mathrm{~m}$ and a resistivity of $600 \Omega \mathrm{m}$ in the Banket Series and $50 \mathrm{~m}$ depth with resistivity value of $500 \Omega \mathrm{m}$ in the Kawere Conglomerate respectively. The electromagnetic conductivity values also show that the general conductivity distribution in the Tarkwa area is $3-32 \mathrm{~S} / \mathrm{m}$. The application of electrical resistivity and electromagnetic techniques separately gives success rate of $80 \%$ and $65 \%$ respectively. An improved success rate of $86 \%$ is achieved combining the two techniques.
\end{abstract}

Keywords: Electrical Resistivity Imaging, Electromagnetic Method, Groundwater

\section{Introduction}

Tarkwa is an important gold mining town located in a sub-humid tropical climate. Due to the gold mining boom, the population of Tarkwa has increased over the years and this has affected the water demand (Kuma and Ewusi, 2009). The major source of potable water in Tarkwa is from the Bonsa Treatment Plant (BTP) operated by the Ghana Water Company Limited (GWCL). Illegal mining activities have polluted the Bonsa River and this has resulted in high treatment cost and irregular water supply. Most inhabitants of Tarkwa have resorted to the construction of boreholes and hand-dug wells to augment water supply from BTP. Groundwater normally does not require treatment and is a cheaper option in the long term.

Dry wells and low yields have been obtained in the difficult hydrogeological units of the Tarkwaian rocks. These can be attributed to non-application of geophysical techniques for borehole siting. When geophysical techniques are employed, the 4electrode electrical resistivity survey technique is normally used. However, the results from the use of this technique have given low success rates for boreholes in the Tarkwa area. According to the Community Water and Sanitation Agency (CWSA), the minimum yield for a mechanised borehole is $40 \mathrm{l} / \mathrm{m}$ and a hand pump is $13 \mathrm{l} / \mathrm{m}$. Obtaining a yield of $40 \mathrm{l} / \mathrm{m}$ is difficult to achieve in the hydrogeologically difficult formations in Tarkwa. Even though the 4-electrode electrical resistivity system and the ERI depend on the same basic principles, the ERI has proven to be more efficient (Ewusi et al., 2009). The ERI technique has proven to be quite successful in groundwater exploration. In Zimbabwe, the ERI was successfully used for groundwater exploration in the Harare greenstone belt (Owen et al., 2005). Ewusi et al. (2009) used the ERI technique to improve success rates and yields of boreholes in the Voltaian Sedimentary Basin, Ghana. Even though these formations have quite different hydrogeological characteristics, the ERI profiles show distinct lithology, boundaries, weak geological zones and fractures that are good indicators for groundwater occurrence (Ewusi et al., 2009). The electromagnetic method (EM) is a well known method used in groundwater exploration. In Ghana, the method has been used for groundwater exploration to improve success rates in the Voltaian Sedimentary Basin (Chegbeleh et al., 2009).

The electrical resistivity survey and electromagnetic methods have been used in groundwater studies because of the close relationship between electrical conductivity and the 
physical properties of aquifers (conductance and resistance) (Goldman and Neubauer, 1994). The ERI and EM methods have been used together for groundwater studies in Ghana (Ewusi and Kuma, 2010) and Kenya (Tsiboah, 2002) and have proven to be very effective and efficient. The aim of this paper is to investigate the hydrogeological conditions of the Tarkwa area using both the ERI and EM geophysical techniques.

\subsection{Study Area}

Tarkwa, the capital of the Tarkwa-Nsuaem Municipality is a mining town located in the Western Region of Ghana. It is accessible by road about $85 \mathrm{~km}$ from Takoradi the regional capital, about $233 \mathrm{~km}$ from Kumasi (Yakubu, 2008) and $287 \mathrm{~km}$ from the national capital, Accra. The location of Tarkwa on a map of Ghana is shown in Fig. 1.

Tarkwa area is dominated by series of ridges and valleys which are parallel to one another with a general northeast-southwest (NE-SW) strike indicating the underlying geology (Quaye 2008; Obosu, 2012). Whitelaw (1929) reported that transverse to the ridges and valleys are smaller valleys and gaps caused by faults and joints. Elevation in Tarkwa ranges from approximately 45 $\mathrm{m}$ to $330 \mathrm{~m}$ above mean sea level. The study area falls within the Ankobra River Basin which is an extensive drainage basin. The area is drained by a number of streams. The most important of these are the Huni River and Bonsa River. These rivers are perennial even though during dry months their flows decrease significantly (Kuma and Ewusi, 2009). Also, flooding during the rainy season is very common.

The Tarkwa area falls within the south-western equatorial climate zone with the season's influenced by moist south-west monsoon winds from the South Atlantic Ocean and dry dust-laden north-east trade winds known as the Harmattan which blows over the Sahara desert from the northern sub-tropical high pressure zone. The Inter Tropical Convergence Zone (ITCZ) crosses over the Tarkwa area two times in a year and results in two peaks in the rainfall figures. The two wet seasons stretch from April to July (with a peak in June) and October to November.

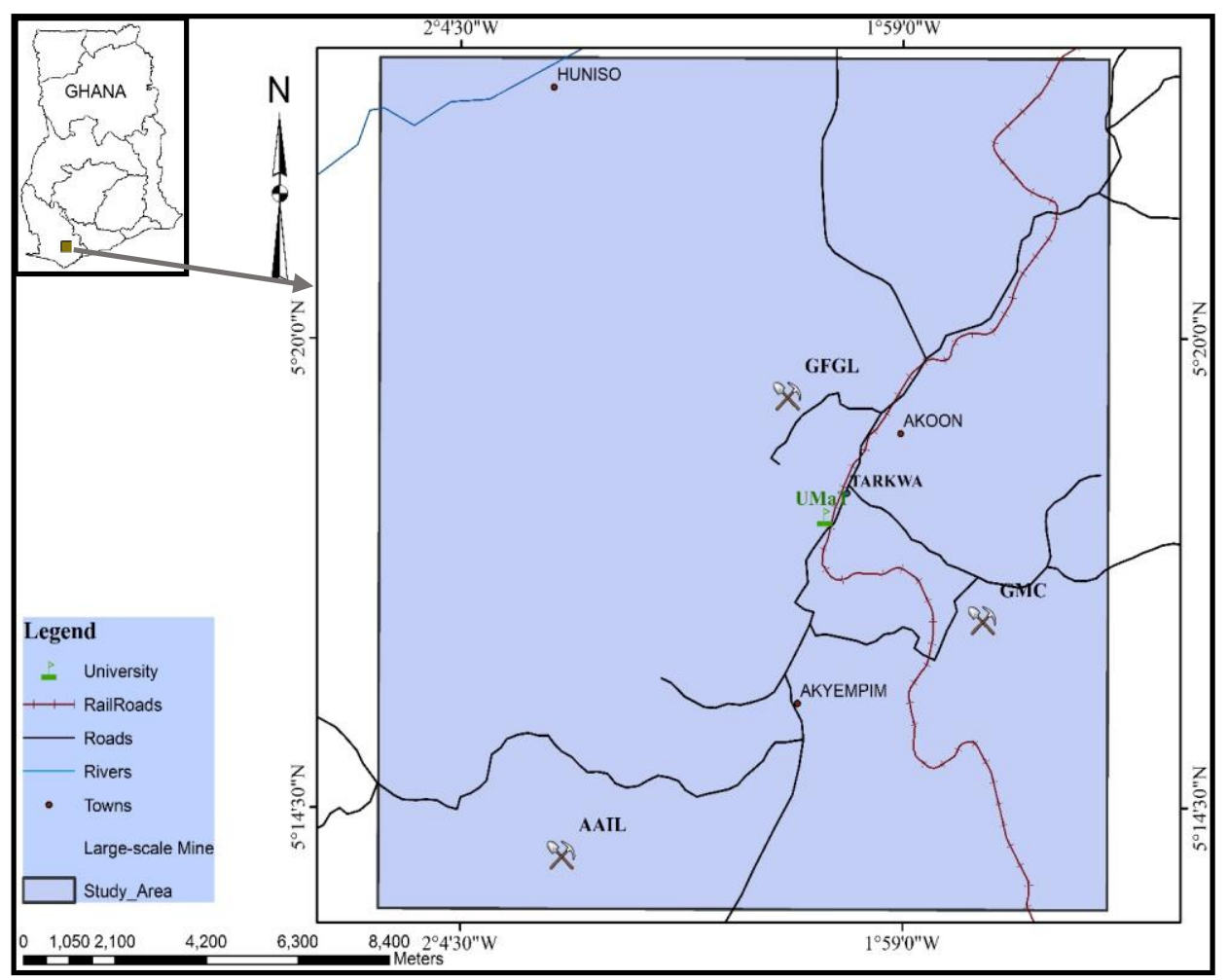

Fig. 1 Location Map of the Study Area 


\subsection{Geology and Hydrogeology}

Tarkwa is hosted on the unconformable contact between the younger Tarkwaian rocks to the west and older Birimian rocks to the east. The Tarkwaian Group comprises a sequence of coarse, clastic, fluviatile meta-sedimentary rocks consisting of the Kawere conglomerates, Banket Series (host of gold mineralisation), Tarkwa Phyllite, and Huni Sandstones and Dompim Phyllite in the direction of younging (Fig. 2). About $20 \%$ of the total Tarkwaian within the Tarkwa area is made up of intrusive igneous rocks (Kuma and Younger, 2001). These rocks range from hypabyssal felsic to basic igneous rocks, which form conformable to slightly transgressive sills with small number of dykes. The Tarkwa area is faulted and jointed with the most prominent joints trending in an east-southeast-west-northwest direction (Hirdes and Nunoo, 1994).

In the Tarkwa area, groundwater occurrence is associated with the development of secondary porosity through fissuring and weathering. The rocks underlying the area lack primary porosity since they are consolidated. Kuma (2002), stated that aquifers in the Tarkwa area possess dual and variable porosity and heterogeneous permeability with limited storage properties. Within an aquifer, folding of the whole area with the widespread presence of joints, faults, fissures and dykes enhances this variability (Kuma and Younger, 2000). Two types of aquifers occur in the study area: the weathered and fractured zone aquifer. The weathered aquifer occurs mainly above the transition zone between fresh and weathered rocks. Due to the presence of clay and silt, these aquifers have high porosity and storage but relatively low permeability. The fractured zone aquifer occurs below the transition zone. They have high transmissivity but low storativity (Kortatsi, 2004).

Conceptual groundwater flow directions show that the two ridges of the Tarkwa Phyllite and Banket Series form a water divide and partition the area into two, namely; northern and southern sectors. On the assumption that both surface and groundwater are hydraulically connected, groundwater flow in the southern sector divide is due south and south-southwest. In the northern sector, groundwater flow directions are generally to the northwest, but inferred to be near the nose of the Huniso syncline (Kuma and Younger, 2000).

\section{Resources and Methods Used}

Both ERI and EM field measurements were taken during the dry season (November-December, 2016). A total of eight (8) ERI and twelve (12) EM surveys were conducted. ERI and EM surveys were conducted to obtain the resistivity and conductivity distribution of rocks at the subsurface. Results from the ERI measurements were inverted to obtain 2D images of the subsurface.

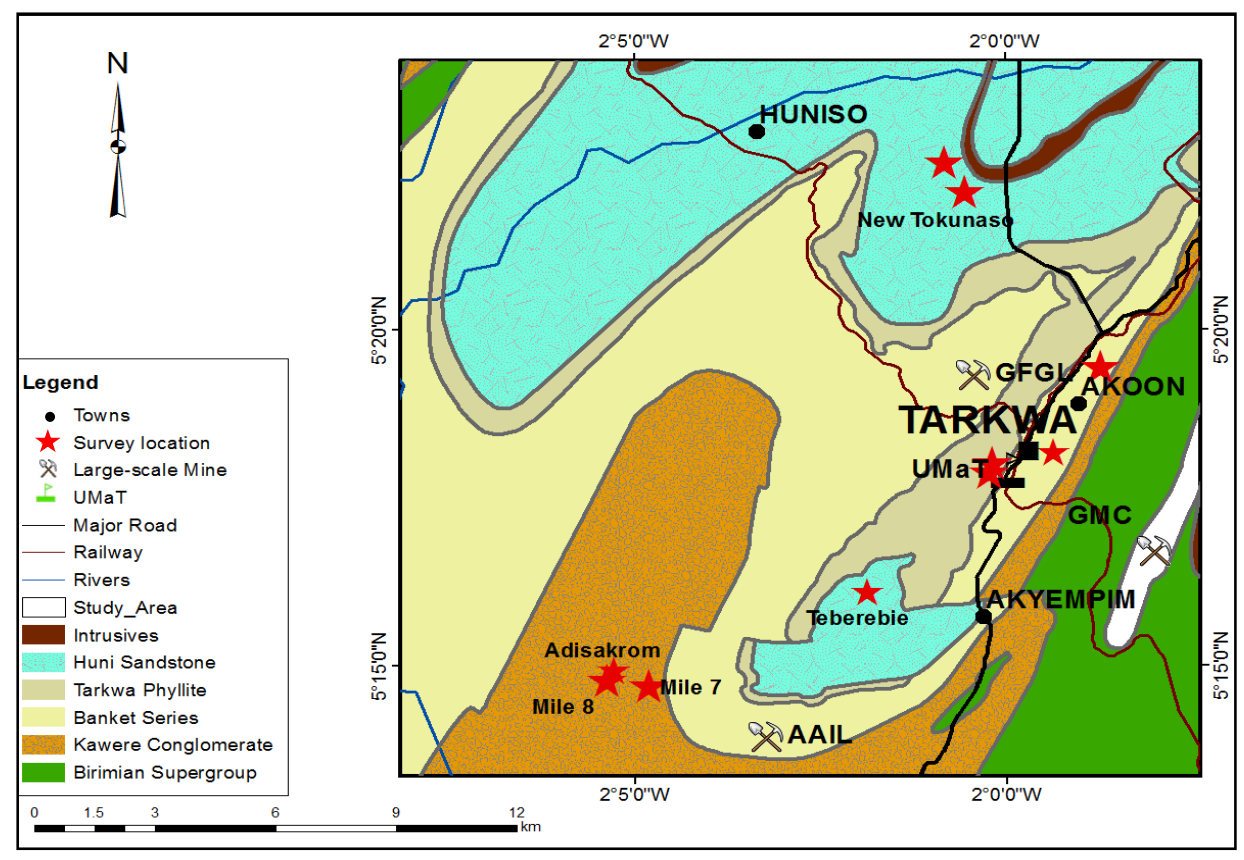

Fig. 2 Geological Map of the Tarkwa Area showing Areas where Geophysical Survey were Conducted 


\subsection{Borehole Calibration}

The ERI and EM methods were used to calibrate existing boreholes in the study area. Both successful and unsuccessful (dry) boreholes were calibrated to obtain the resistivity and conductivity values which indicate the presence of aquifers in the Tarkwa area. In places where boreholes were not located, hand-dug wells were calibrated and the results from these were used for further analysis.

\subsection{Electrical Resistivity Survey}

The conventional resistivity survey makes use of four electrodes; two current electrodes and two potential electrodes. The electrodes are configured to suit the purpose for which the survey is conducted. With the four electrode resistivity survey, electrical profiling and sounding give a 1D horizontal and vertical information about the subsurface (Owen et al., 2005). The advent of computers in resistivity surveys has made it possible for multiple electrodes to be connected to multicore cables which are connected to a resistivity meter (Dahlin, 1996). The computer (resistivity meter) has been set-up to automatically select combinations of four electrodes at any given time, and thus produces a 2D data set. The ERI techniques gives a 2D information of the subsurface. The apparent resistivity in rocks is given by equation 1 .

$$
\rho_{\mathrm{a}}=\frac{2 \pi \mathrm{aV}}{\mathrm{I}}
$$

Where $\rho_{\mathrm{a}}$ is the apparent resistivity $(\Omega \mathrm{m}), \mathrm{V}$ is the electric potential, a is distance from a point electrode and I is the electric current.

\subsection{ERI data acquisition and processing}

ABEM Terrameter LS was used for field data collection. The equipment consist of a resistivity meter, cables and electrodes. The meter was connected to a $12 \mathrm{~V}$ DC battery. Readings were taken using three configurations; Schlumberger, Wenner and dipole dipole and the most suitable and efficient configuration for the area was selected. Traverses were selected to intercept lineaments in the area and also along existing boreholes. The maximum traverse length for ERI surveys was $400 \mathrm{~m}$ with an electrode spacing of 10 $\mathrm{m}$.

Data sets that were acquired are apparent resistivity and were inverted to obtain true electrical resistivity distribution of the study area using RES2DINV software. The inversion software is based on smoothness-constrained least squares inversion by quasi-Newton optimisation method (Gupta et al., 2014; Loke, 1999; Loke and Baker,
1996). The inversion method minimises the difference between the measured and calculated apparent resistivity values. The program uses an iterative method whereby starting from an initial model, the program tries to find an improved model whose calculated apparent resistivity values are closer to the measured values. One disadvantage of the inversion program is that the user has a limited influence on the inversion routine (Ewusi, 2006).

\section{EM Survey}

EM surveys are based on measurement of magnetic fields associated with alternating currents induced in subsurface conductors by primary magnetic fields (Griffiths and King, 1981). A magnetic field is generated around the coil which when held near the earth induces an electrical field that travels through the earth at different strengths. Changes which are related to electrical properties of the earth can be measured either with time or distance using a receiver (Fetter, 2001). In EM surveys, the quantity of the rock which is measured is the conductivity. Electrical conductivity of rocks can be influenced by the water content, clay content, metal content and permeability. The apparent conductivity in rocks and soils is given as:

$$
\sigma_{\mathrm{a}}=\frac{4}{\omega \mathrm{s}^{2} \mu_{\mathrm{o}}}\left(\frac{\mathrm{H}_{\mathrm{s}}}{\mathrm{H}_{\mathrm{p}}}\right)
$$

Where $\sigma_{\mathrm{a}}$ is the apparent conductivity $(\mathrm{mS} / \mathrm{m}), \omega$ is $2 \pi \mathrm{f}$, where $\mathrm{f}$ is the frequency of the electromagnetic wave $(\mathrm{Hz}), \mathrm{s}$ is the distance between the transmitter and receiver coils $(\mathrm{m}), \mu \mathrm{o}$ is the permeability of free space, $\mathrm{Hs}$ is the secondary magnetic field at the receiver coil and Hp primary magnetic field at the receiver coil.

\subsection{EM Data Acquisition and Processing}

EM conductivity survey was conducted using the Geonics EM34-3 meter. The equipment is made up of two coils; transmitter and receiver coils, with their corresponding consoles. On all profiles, the transmitter was always ahead of the receiver. The transmitter was placed at a stationary point while the receiver was moved back and forth until it attained the correct intercoil spacing, and the conductivity value recorded from the receiver. Readings were taken at $10 \mathrm{~m}$ interval using the 20 $\mathrm{m}$ and $40 \mathrm{~m}$ cable separately, for both vertical and horizontal dipoles. In cases where readings from the $20 \mathrm{~m}$ cable were inadequate, the $40 \mathrm{~m}$ cable was used. For the $20 \mathrm{~m}$ cable, the horizontal and vertical dipole coil orientations probe to depth of 15 and $30 \mathrm{~m}$ respectively (McNeill, 1980. Two methods were employed to select potential groundwater accumulation zones; the crossover method (Anon, 2003) and the peak amplitude method (Ewusi and Kuma 2010). 


\section{Results and Discussion}

Results of ERI and EM profile measurements in the four lithostratigraphic units of the Tarkwaian Group have been presented in three folds; borehole calibration, ERI survey and EM survey.

\subsection{Borehole Calibration Results}

Two boreholes were used in the calibration: a high yielding borehole located at UMaT and a dry borehole located at Adisakrom (Figs. 3 and 4). The high yielding and dry boreholes are within the Tarkwa Phyllite and Kawere Conglomerate lithostra-tigraphic unit of the Tarkwaian respectively.

Along the ERI profile, a borehole located at station $200 \mathrm{~m}$ is situated in a low resistivity zone of 80 $200 \Omega \mathrm{m}$ and occurs to a depth of $60 \mathrm{~m}$ (Fig. 3a). The resistivity distribution in the area is between 70 and $93000 \Omega \mathrm{m}$ with three distinct resistivity layers. The first layer which has a relatively low resistivity of $70-1000 \Omega \mathrm{m}$ and occurs between depths of $4-30 \mathrm{~m}$ for stations $0-180 \mathrm{~m}$ and the between depths of $4-60 \mathrm{~m}$ for stations $180-300$ $\mathrm{m}$. The second resistivity layer has values between 1000 and $4000 \Omega \mathrm{m}$, with a thickness of $10 \mathrm{~m}$ which underlies the low resistivity layer. The third layer has resistivity values between $12000-93$ $000 \Omega \mathrm{m}$ with a thickness of $18 \mathrm{~m}$ and underlies the intermediate resistivity layer. The ERI modelled sections show that between station $0-180 \mathrm{~m}$ the aquifer has a relatively small thickness compared to the thickness of the aquifer that is observed between stations 180 and $300 \mathrm{~m}$.

On the EM profile (Fig. 3b), a crossover is observed at station $200 \mathrm{~m}$ (borehole location). Between stations 200 and $350 \mathrm{~m}$ on the EM profile, six additional crossovers are observed to occur at stations $210 \mathrm{~m}, 220 \mathrm{~m}, 230 \mathrm{~m}, 270 \mathrm{~m}, 280 \mathrm{~m}$ and $300 \mathrm{~m}$. These crossovers give an indication of the presence of groundwater that has been accumulated in fractures in the subsurface along the profile. The water-bearing zone is observed from a depth of 15 $\mathrm{m}$ through to $30 \mathrm{~m}$ and beyond. This supports results that were obtained from the ERI survey.

A dry borehole located at Adisakrom was also calibrated using both ERI and EM methods. The results have been presented on Figs. $4 \mathrm{a}$ and $4 \mathrm{~b}$. The survey length was $200 \mathrm{~m}$, using an electrode spacing of $5 \mathrm{~m}$ and probing to a depth of $37 \mathrm{~m}$. It was observed from the modelled section that the area is underlain by moderately high resistivity rocks of $800-6000 \Omega$ m. A resistivity value of 99 $\Omega \mathrm{m}$ occurs between stations $100 \mathrm{~m}$ and $155 \mathrm{~m}$ at a depth of $6 \mathrm{~m}$ to $10 \mathrm{~m}$. Occurring underneath this area is a resistivity of $800 \Omega \mathrm{m}$, which is sandwiched between a relatively lower resistivity value of $300 \Omega \mathrm{m}$. Between depths of $2-6 \mathrm{~m}$, from station $70 \mathrm{~m}$ to $85 \mathrm{~m}$ occurs a very high resistivity rock of $6000 \Omega \mathrm{m}$. The non-uniform distribution of resistivity values is very characteristic of the rocks that exist in the area. Outcrops of conglomerate were observed to be in the area. A borehole drilled at station $145 \mathrm{~m}$ had a very low yield less than the minimum yield of $13 \mathrm{l} / \mathrm{m}$ for construction and was therefore backfilled.

EM survey conducted along the same profile on which the borehole is located at Adisakrom shows a wavy nature for both $20 \mathrm{HD}$ and VD modes (Fig. 4b). Negative conductivity values were recorded for the $20 \mathrm{VD}$ mode. This could be an indication of a geologic anomaly or buried objects. In the case of the $20 \mathrm{HD}$ mode, readings were observed to be positive along the profile. The maximum conductivity value recorded along the profile was $17 \mathrm{mS} / \mathrm{m}$ which was observed at station $30 \mathrm{~m}$ (Fig. 4b). The dry borehole which is located at station $145 \mathrm{~m}$ recorded conductivity values of -1 (VD mode) and $8 \mathrm{mS} / \mathrm{m}$ (HD mode). There was also no crossover on the profile using the EM.

\section{ERI Results}

Four modelled sections were selected to represent all the lithostratigraphic units of the Tarkwaian. These modelled sections represent distinct characteristics amongst the results obtained.

\subsection{Comparison of ERI Protocols}

The three configurations (Schlumberger, Wenner and Dipole-dipole) were analysed simultaneously to select the most suitable and efficient protocol for groundwater exploration in the Tarkwa area. Modelled results from field measurements using these three protocols are presented in Fig. 5. Results from the three configurations suggest that the area is underlain by very low to very high resistivity rocks ranging from 33 to $100000 \Omega \mathrm{m}$ giving a wide resistivity contrast of the modelled sections.

From the modelled results, it is observed that generally, there are three distinct resistivity layers, with the sections showing increasing resistivity with depth. The first layer has a resistivity distribution of between 70 and $500 \Omega \mathrm{m}$ with depth from surface to $50 \mathrm{~m}$. The second resistivity layer occurs between depths of $50-62 \mathrm{~m}$ with a resistivity distribution of between 1000 and 10000 $\Omega \mathrm{m}$ and the last layer has a resistivity greater than $10000 \Omega \mathrm{m}$ that occurs beyond a depth of $62 \mathrm{~m}$. 


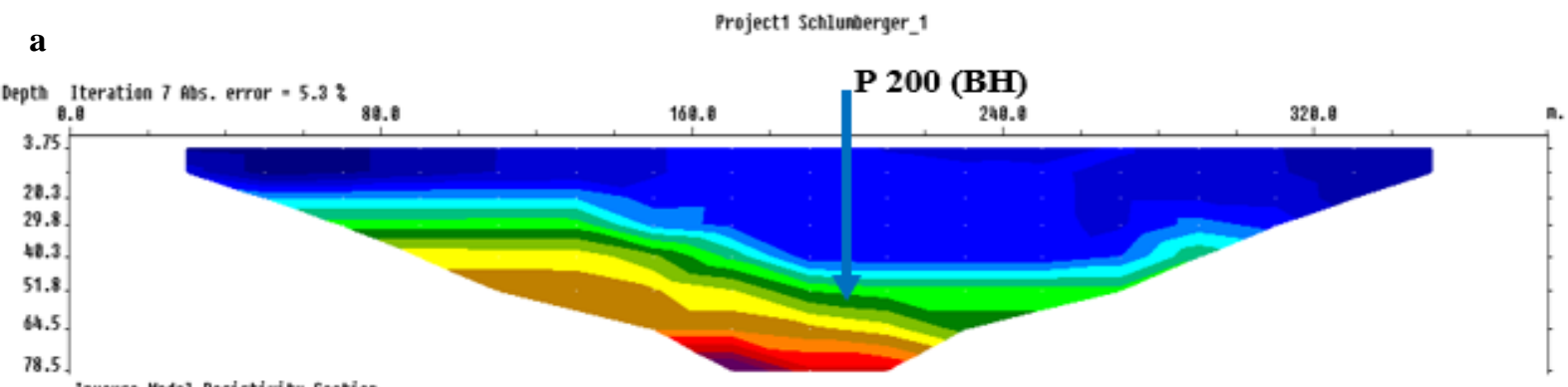

Inverse Nodel Resistivity Section

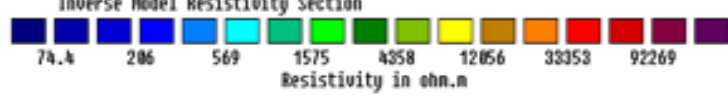

Unit electrote spacing is $20.0 \mathrm{~m}$.

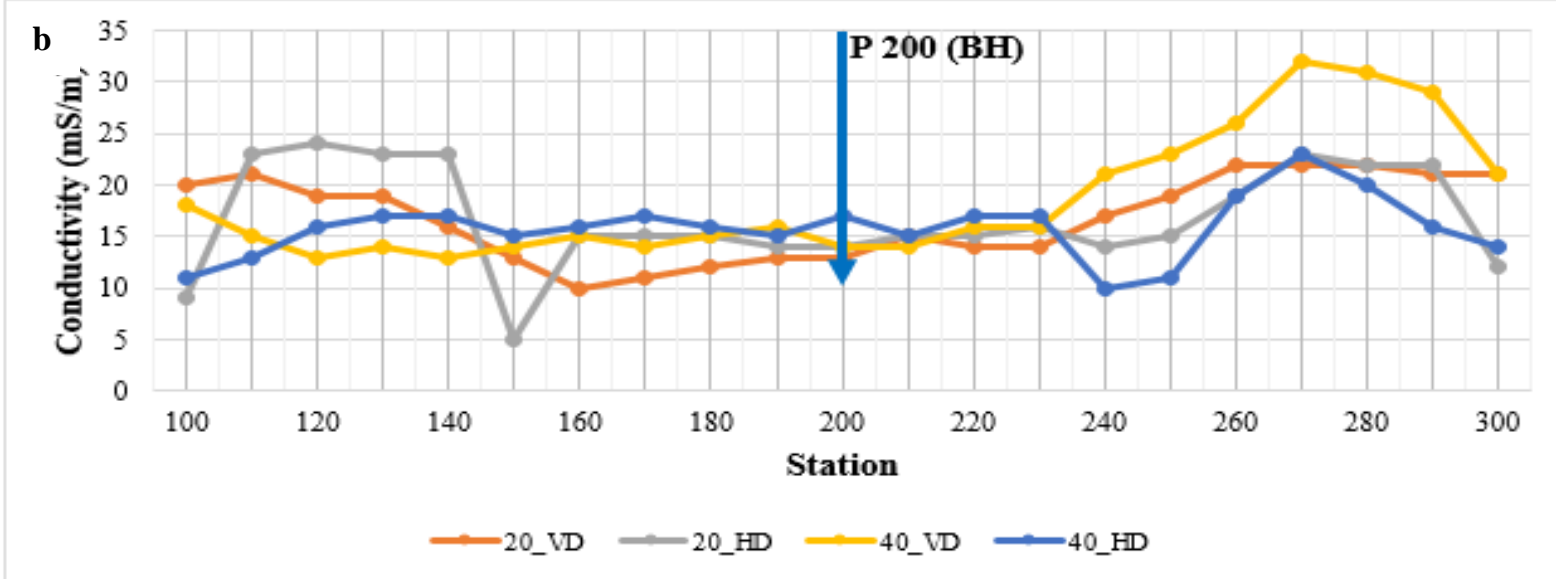

Fig. 3 Borehole Calibration using (a) ERI and (b) EM Techniques at UMaT
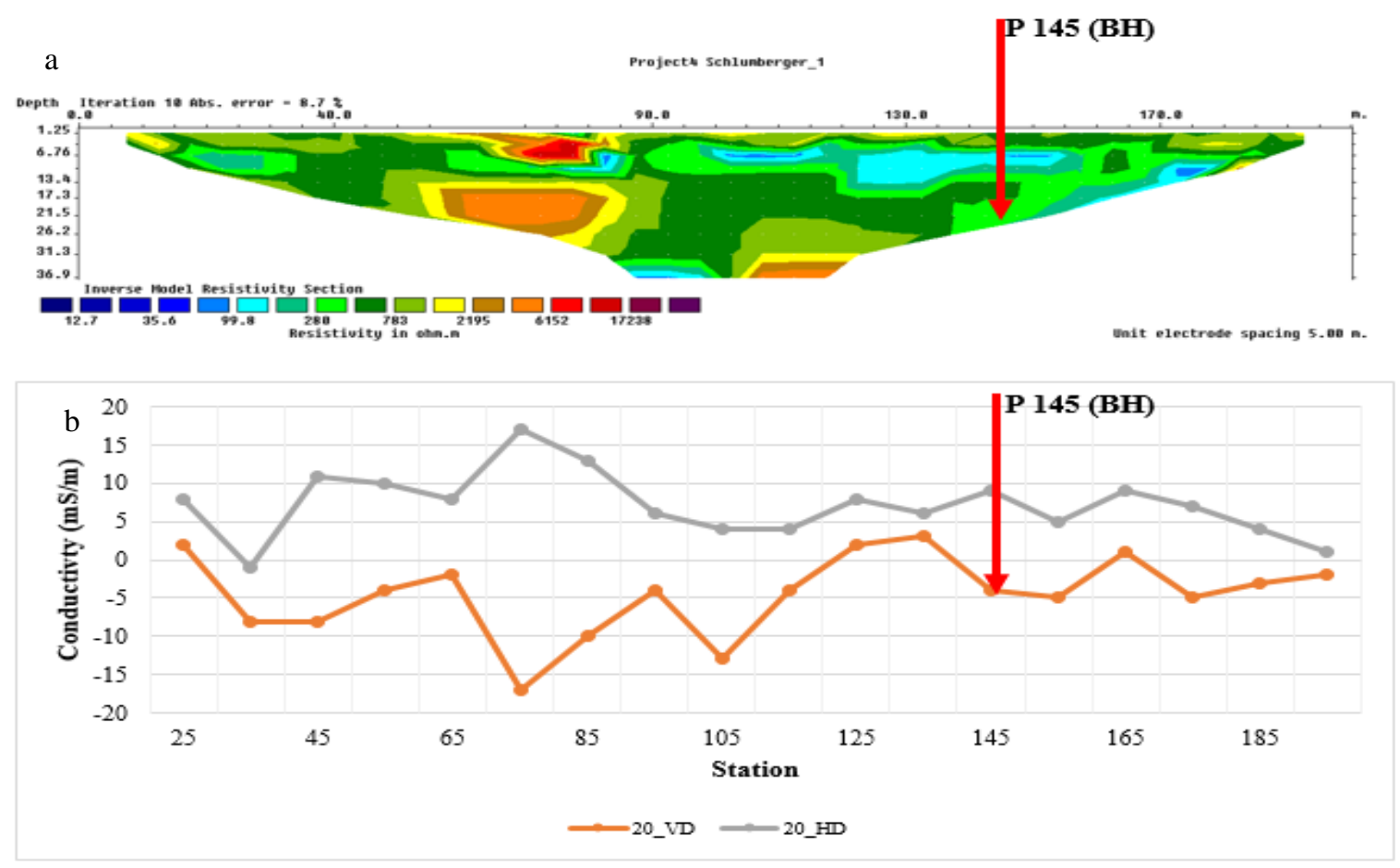

Fig. 4 Borehole Calibration using (a) ERI and (b) EM Techniques at Adisakrom 
Results from the three protocols were similar. However, unlike the Schlumberger and Wenner configurations (Figs. 5a and 5b), the Dipole-dipole configuration does not show a distinct layering of the rocks. The Dipole-dipole configuration shows three bowl-shapes occurring between stations 80 and $160 \mathrm{~m}$, stations $200 \mathrm{~m}$ and $260 \mathrm{~m}$ and stations $260 \mathrm{~m}$ and $300 \mathrm{~m}$ with varying resistivity values of $32-100 \Omega \mathrm{m}, 500-700 \Omega \mathrm{m}$ and $50-300 \Omega \mathrm{m}$ respectively (Fig. 5c). The depth of investigation for both Schlumberger and Wenner configurations is $79 \mathrm{~m}$ and $94 \mathrm{~m}$ for the Dipole-dipole configuration.
The Wenner and Schlumberger configurations probe at a swallower depth compared to the Dipole-dipole. The Dipole-dipole is therefore ideal for surveying at greater depth. Generally, the Schlumberger and Wenner configurations have good signal strength because of their electrode configuration. For this research, results of the Schlumberger configuration correlated well with results obtained for the EM survey. The Schlumberger configuration was therefore used for subsequent analysis.

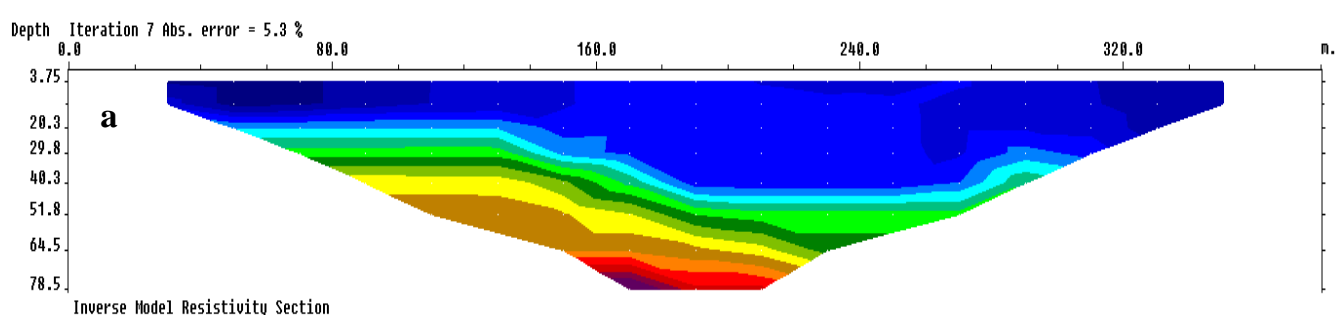

Inverse Model Resistivity Section

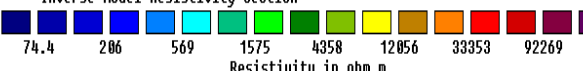

Unit electrode spacing is $28.8 \mathrm{~m}$.

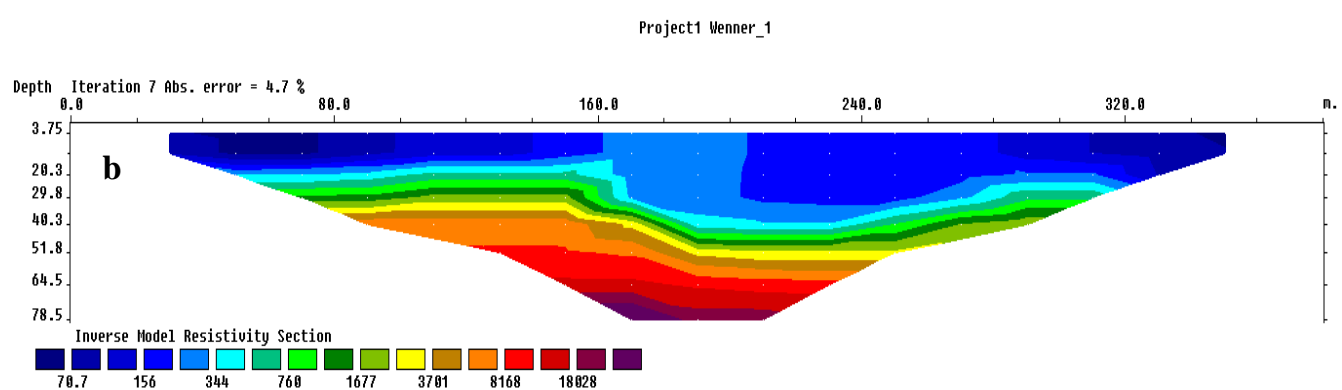

${ }_{70.7} \square_{156} \square{ }_{344} \square \square \square \square \square \square{ }_{1677} \square \square_{8168} \square_{18028} \square \square$

Unit electrode spacing is $28.8 \mathrm{~m}$.

Project1 Dipoledipole 1

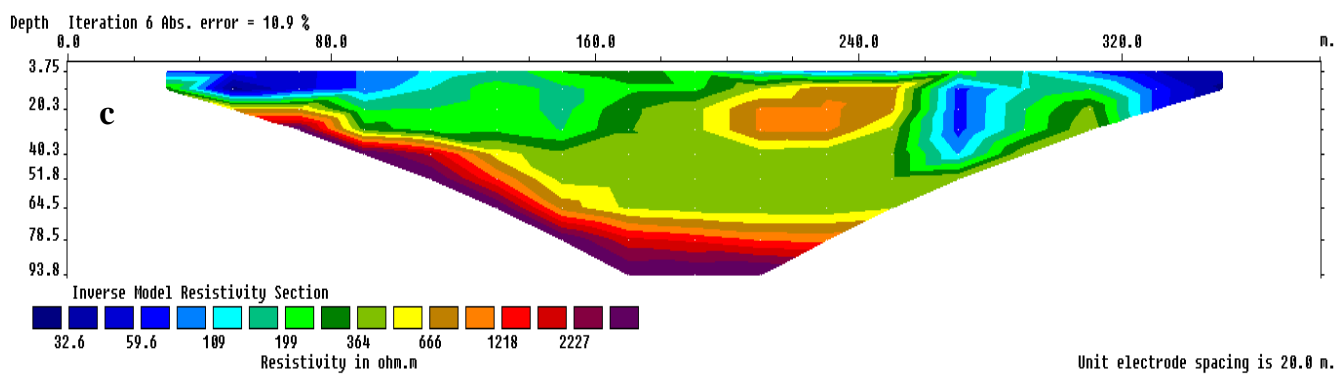

Fig. 5 Comparison of ERI Protocols using (a) Schlumberger, (b) Wenner and (c) Dipole-dipole Configurations 


\subsection{Lithology-based ERI Results}

Modelled section from each lithostratigraphic unit of the Tarkwaian is presented in Fig. 6. These results were selected because they represent distinct characteristics of the geology where the traverses were surveyed. Results from ERI survey conducted in the Huni Sandstone and Dompim Phyllite at New Tokunaso show a three distinct horizontally layered resistivity units (Fig. 6a). The first unit has a resistivity distribution of between 100 and $400 \Omega \mathrm{m}$ and occurs to a depth of $25 \mathrm{~m}$ and is distributed uniformly along the traverse. The second unit's resistivity values ranges from 500 to $1200 \Omega \mathrm{m}$ and occurs to a depth of $35 \mathrm{~m}$. The third unit has a resistivity value greater than $1500 \Omega \mathrm{m}$ occurring beyond a depth of $40 \mathrm{~m}$. The high resistivity material that occurs beyond $40 \mathrm{~m}$ is an indication that this zone might not have conditions that are favourable for groundwater accumulation and flow. The area is interpreted to be underlain by unweathered and unfractured quartzite at a $40 \mathrm{~m}$ depth and deeper. The low resistivity zone occurring at a relatively shallow depth is ideal for siting shallow boreholes and hand-dug wells.

Modelled resistivity pseudosection of ERI survey conducted in the Tarkwa Phyllite at UMaT shows generally, a resistivity distribution of between 50 and $2400 \Omega \mathrm{m}$ (Fig. 6b). Along the traverse, a high resistivity zone of values greater than $1400 \Omega \mathrm{m}$ is observed between stations 25 and $150 \mathrm{~m}$. Between stations 180 and $320 \mathrm{~m}$, low resistivity zones of values between 50 and $100 \Omega \mathrm{m}$ occur to a depth of $50 \mathrm{~m}$ defining a bowl-shaped figure. This phenomenon according to Ewusi and Kuma (2010), may be related to the accumulation of groundwater. Along the traverse, boreholes are located at stations 200 and $260 \mathrm{~m}$.

Fig. 6c shows modelled resistivity pseudosection in the Banket Series at New Atuabo. The resistivity distribution of the area is between 100 and 19300 $\Omega \mathrm{m}$. Between stations 25 and $160 \mathrm{~m}$, low resistivity zones of $100-500 \Omega \mathrm{m}$ are encountered to a depth of $30 \mathrm{~m}$ and to a depth of $20 \mathrm{~m}$ between stations 260 and $340 \mathrm{~m}$. Between stations 160 and $260 \mathrm{~m}$, low resistivity zones are encountered to depths of 45 to $55 \mathrm{~m}$. A very high resistivity zone from 4000 to $19300 \Omega \mathrm{m}$ is observed between stations 270 and $310 \mathrm{~m}$ at a depth of $30 \mathrm{~m}$. The very high resistivity zone occurs as a patch along the traverse. Along the traverse, two hand-dug wells are located at stations 40 and $120 \mathrm{~m}$. The low resistivity layer in which the hand-dug wells are located are up to a depth of $25 \mathrm{~m}$ confirming the presence of shallow groundwater.

Fig. 6d shows modelled resistivity pseudosection in the Kawere Conglomerate at Adeyie (Mile 8). The resistivity distribution of the area is between 100 and $2500 \Omega \mathrm{m}$ with three resistivity units. The first unit has a resistivity value of between 100 and 400 $\Omega \mathrm{m}$ and is underlain by the second resistivity unit of value between 500 and $800 \Omega \mathrm{m}$. The first and second resistivity units form a basin (bowl-shape) structure. This structure on a resistivity profile is interpreted as being favourable for groundwater accumulation. At station $160 \mathrm{~m}$, a high resistivity unit having values between 1000 and $2500 \Omega \mathrm{m}$ is observed at a depth of $65 \mathrm{~m}$. A borehole with marginal yield is located at station $200 \mathrm{~m}$.

From the ERI results, a summary of lithology and their resistivity ranges that are related to groundwater occurrence in the Tarkwa area is presented in Table 1. Generally, the resistivity ranged from $100-3000 \Omega m$ in the Huni Sandstone and Dompim Phyllite, $60-100000 \Omega \mathrm{m}$ in the Tarkwa Phyllite, $100-19300 \Omega \mathrm{m}$ in the Banket Series and $150-3200 \Omega \mathrm{m}$ in the Kawere Conglomerate.

\section{EM Results}

EM surveys were conducted in the study area to determine conductivity values of rocks in each lithostratigraphic unit of the Tarkwaian rock and their relation to groundwater conditions. The results have been presented as EM profiles of conductivity against distance (station) (Fig. 8). Two techniques were used for EM interpretation; the crossover and the peak amplitude techniques.

Fig. 7a shows EM results in the Huni Sandstone and Dompim Phyllite at New Tokunaso (Fig. 2). Along the profile, it is observed that conductivity values are not uniformly distributed. The maximum conductivity value measured was $11 \mathrm{mS} / \mathrm{m}$ that occurred at station $200 \mathrm{~m}$ using the $40 \mathrm{VD}$ mode. The location of a borehole along profile $\mathrm{A}$ is observed to be on a classical crossover. Stations 240 and $250 \mathrm{~m}$ also occur on a crossover. Negative conductivity values are observed along the profile especially with the results from the $20 \mathrm{HD}$ mode.

The results from the EM survey conducted in the Tarkwa Phyllite at UMaT is presented in Fig. 8b. The conductivity distribution of the area is between 5 and $24 \mathrm{mS} / \mathrm{m}$. The profile is divided into two sections; section A and section B. Section A starts from station 150 to $230 \mathrm{~m}$ and has a uniform conductivity that ranges between $10 \mathrm{mS} / \mathrm{m}$ and 15 $\mathrm{mS} / \mathrm{m}$. The relatively high conductivity is attributed to the presence of clay material that is saturated with water. A high yielding borehole is located at station $200 \mathrm{~m}$ and occurs on a classical crossover on the EM profile. Along the profile, crossovers were observed at other stations $(210,270,280$ and $290 \mathrm{~m}$ ). This gives an indication of the presence of potential water bearing zones. 

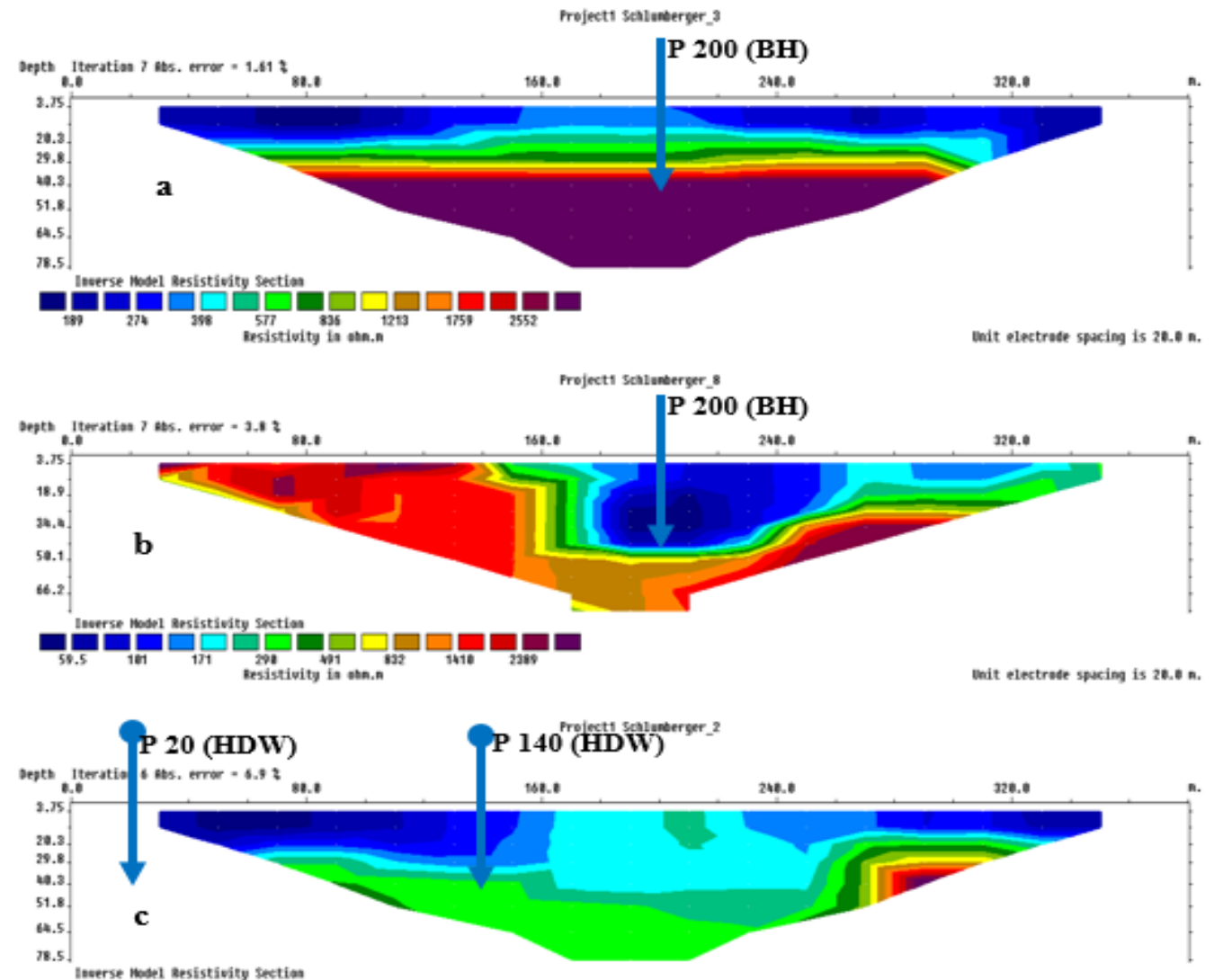

口 1113 isistivity is ath.n
Project sealunterger_o

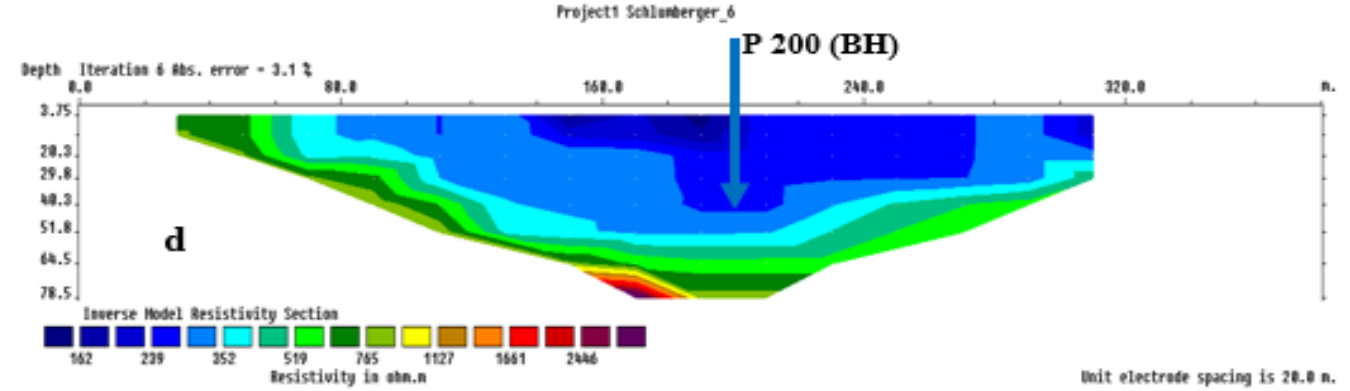

Fig. 6 Modelled Sections of results from 2D ERI of the (a) Huni Sandstone and Dompim Phyllite (b) Tarkwa Phyllite (c) Banket Series and (d) Kawere Conglomerate

Table 1 Lithology and Resistivity Range related to Groundwater Occurrence in the Tarkwa Area

\begin{tabular}{|l|l|l|l|}
\hline Lithology & Description & Resistivity $(\mathbf{\Omega m})$ & Hydrogeological Potential \\
\hline \multirow{4}{*}{ Huni Sandstone } & Overburden & $150-250$ & Fairly good groundwater potential \\
\cline { 2 - 4 } & Fractured zone & $400-1200$ & Good groundwater potential \\
\cline { 2 - 4 } & Bedrock & $1800-4600$ & $\begin{array}{l}\text { Very poor groundwater potential, bedrock } \\
\text { occurring at a very shallow depth }\end{array}$ \\
\hline \multirow{3}{*}{ Banket Series } & Overburden & $32-200$ & Good groundwater potential \\
\cline { 2 - 4 } & Fractured zone & $240-1000$ & Very good groundwater potential \\
\cline { 2 - 4 } & Bedrock & $8000-93000$ & Poor groundwater potential \\
\hline \multirow{4}{*}{ Kawere Conglomerate } & Overburden & $131-280$ & Good groundwater potential \\
\cline { 2 - 4 } & Fractured zone & $500-1200$ & Very good groundwater potential \\
\cline { 2 - 4 } & Bedrock & $4600-19300$ & Poor groundwater potential \\
\cline { 2 - 4 } & Overburden & $165-240$ & $\begin{array}{l}\text { Very poor groundwater potential, overburden } \\
\text { occurring to a deeper depth }\end{array}$ \\
\cline { 2 - 4 } & Fractured zone & $400-800$ & Good groundwater potential \\
\hline & Bedrock & $1200-2500$ & Very poor groundwater potential \\
\hline
\end{tabular}


In the case of section $\mathrm{B}$, which occurs between station $240 \mathrm{~m}$ and station $350 \mathrm{~m}$, the conductivity values are observed to increase from 15 to 25 $\mathrm{mS} / \mathrm{m}$ as compared to section A. The maximum conductivity value for the profile was recorded at station $320 \mathrm{~m}$ with a value of $24 \mathrm{mS} / \mathrm{m}$ using the 20 $\mathrm{m}$ HD mode. This suggests the existence of a potential water bearing zone. The peak amplitude method and the crossover method coincide at station $270 \mathrm{~m}$. This is interpreted as possible groundwater accumulation zone.

Results for an EM survey conducted in the Banket Series at New Atuabo is presented in Fig. 7c. Along the profile, a constant conductivity value of $3 \mathrm{mS} / \mathrm{m}$ is observed from station 0 to $70 \mathrm{~m}$. An open hand-dug well located at station $20 \mathrm{~m}$ was observed to have a static water level of $1 \mathrm{~m}$ from the surface. Conductivity values for the HD mode increased between station $80 \mathrm{~m}$ and $140 \mathrm{~m}$. Another hand-dug located along the profile at station $110 \mathrm{~m}$. From the profile, it can be inferred that the area has a water-bearing zone occurring at a shallow depth of about $15 \mathrm{~m}$. Along the profile, a classical crossover was observed at station $150 \mathrm{~m}$ and this gives an indication of possible groundwater accumulation in the area.

Fig. 7d shows results of EM survey conducted at Mile 8 (Adeyie). An erratic behaviour of conductivity values is observed along the profile especially with the $20 \mathrm{VD}$ mode. Unlike the VD mode, the HD mode shows a homogenous reading along the profile except for stations 130, 140, 200 and $250-300 \mathrm{~m}$. Between stations 120 and $140 \mathrm{~m}$ using the $20 \mathrm{HD}$, it was observed that the conductivity values increased. This is attributed to weathered overburden that is saturated with water to a depth of $15 \mathrm{~m}$ below the surface. The values obtained from the $20 \mathrm{VD}$ mode varies in conductivity, ranging between $1-13 \mathrm{mS} / \mathrm{m}$. Stations 100 to $190 \mathrm{~m}$ recorded a relatively high conductivity values except at stations 140 and 150 m. Between stations 200 and $260 \mathrm{~m}$, low conductivity values were recorded with values between 2 and $5 \mathrm{mS} / \mathrm{m}$. Stations 270 to $300 \mathrm{~m}$ also recorded high conductivity values. Generally, the conductivity values along the profile were observed to be high from the start (station $100 \mathrm{~m}$ ), the values then dropped at some point along the profile and rose again at the end of the profile. A low water yielding borehole is located at station $200 \mathrm{~m}$. The borehole location was observed not to have occurred on a crossover or on a peak amplitude. Conductivity values of 1 and $3 \mathrm{mS} / \mathrm{m}$ were recorded using the $20 \mathrm{HD}$ and $20 \mathrm{VD}$ coil orientations respectively. However, a classical crossover was observed at station $120 \mathrm{~m}$ which gives an indication of good groundwater potential. Using the peak amplitude method, stations 110, 180 and $280 \mathrm{~m}$ can also be interpreted as having good groundwater potential. EM Conductivity values that are related to groundwater occurrence in the Tarkwa area are summarised in Table 2 .

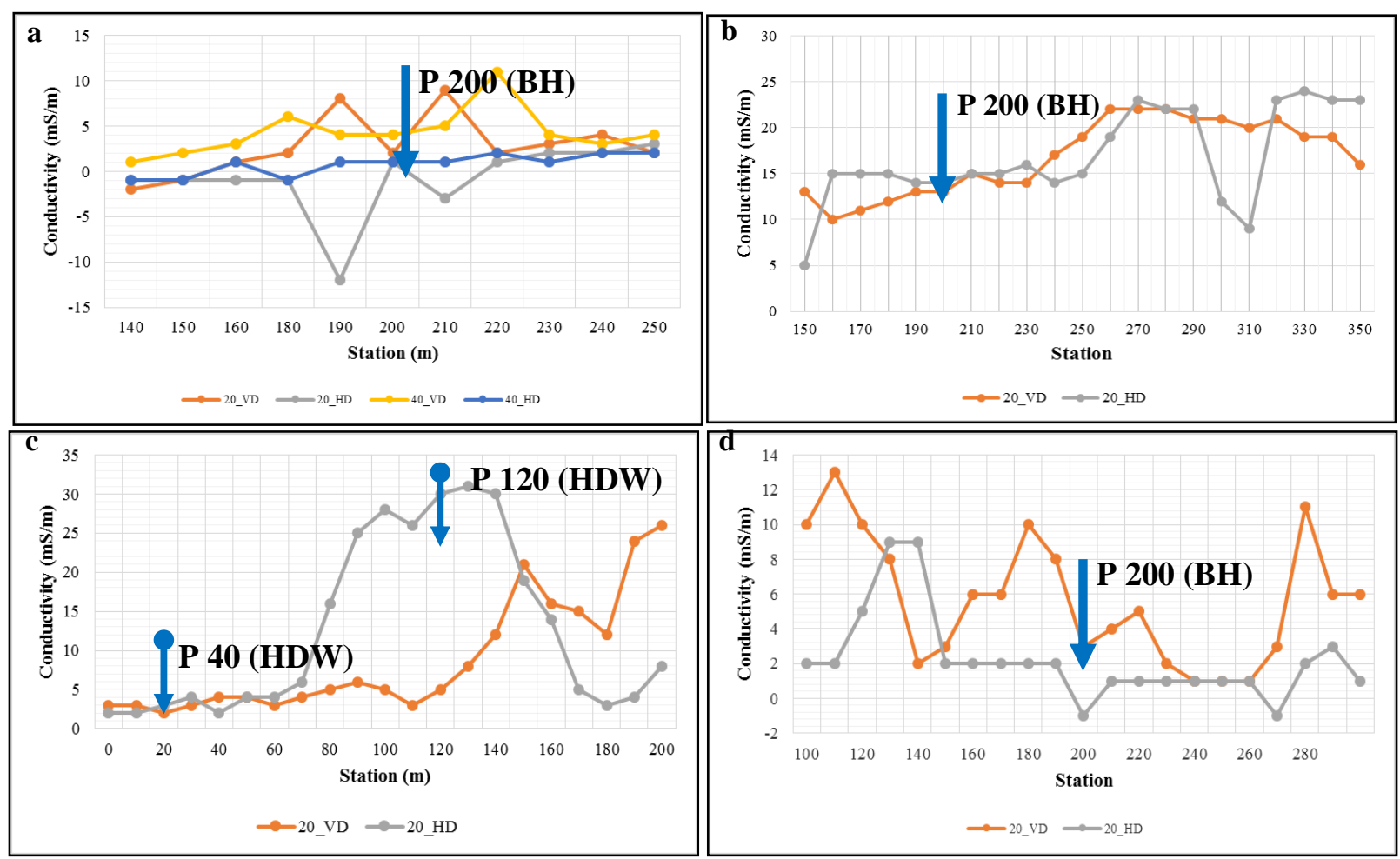

Fig. 7 EM Terrain Conductivity Measurement in the (a) Huni Sandstone and Dompim Phyllite, (b) Tarkwa Phyllite, (c) Banket Series and (d) Kawere Conglomerate 


\subsubsection{Negative and High Conductivity Values}

In some of the conductivity measurements, negative and extremely high values were recorded. Normally, negative conductivity values gives an indication that there may be vertical fractures that occur at depth. However, not all negative conductivity values are indicative of the presence of vertical fractures. In some areas, negative conductivity values were observed along the entire profile (Fig. 8a). Careful observations of these terrains show that the presence of conductive materials and electrical devices such as transformers, high tension cables etc might have had an effect on the conductivity readings. In cases where the conductivity values were too high to be recorded by the equipment, negative conductivity values were recorded. Another possible reason why negative conductivity values were recorded may be attributed to buried materials underground. The study area has a history of about hundred years of mining. There was underground mining in the past before surface mining. It is possible some materials were left underground after the closure of the underground mine that might influence the conductivity readings.

Fig. $8 \mathrm{~b}$ shows that high conductivity values were recorded in the Banket Series at Nzema line which are outliers compared to the background values. Between stations 60 and $80 \mathrm{~m}$, very high conductivity values between 87 and $146 \mathrm{mS} / \mathrm{m}$ were recorded using the $20 \mathrm{HD}$. Metal poles and roofing sheets were observed along the traverse but the high values can be attributed to buried conductive materials underground. A borehole is located $30 \mathrm{~m}$ on the profile on a crossover. Another crossover was observed is observed at station $90 \mathrm{~m}$ with a conductivity value of $22 \mathrm{mS} / \mathrm{m}$.
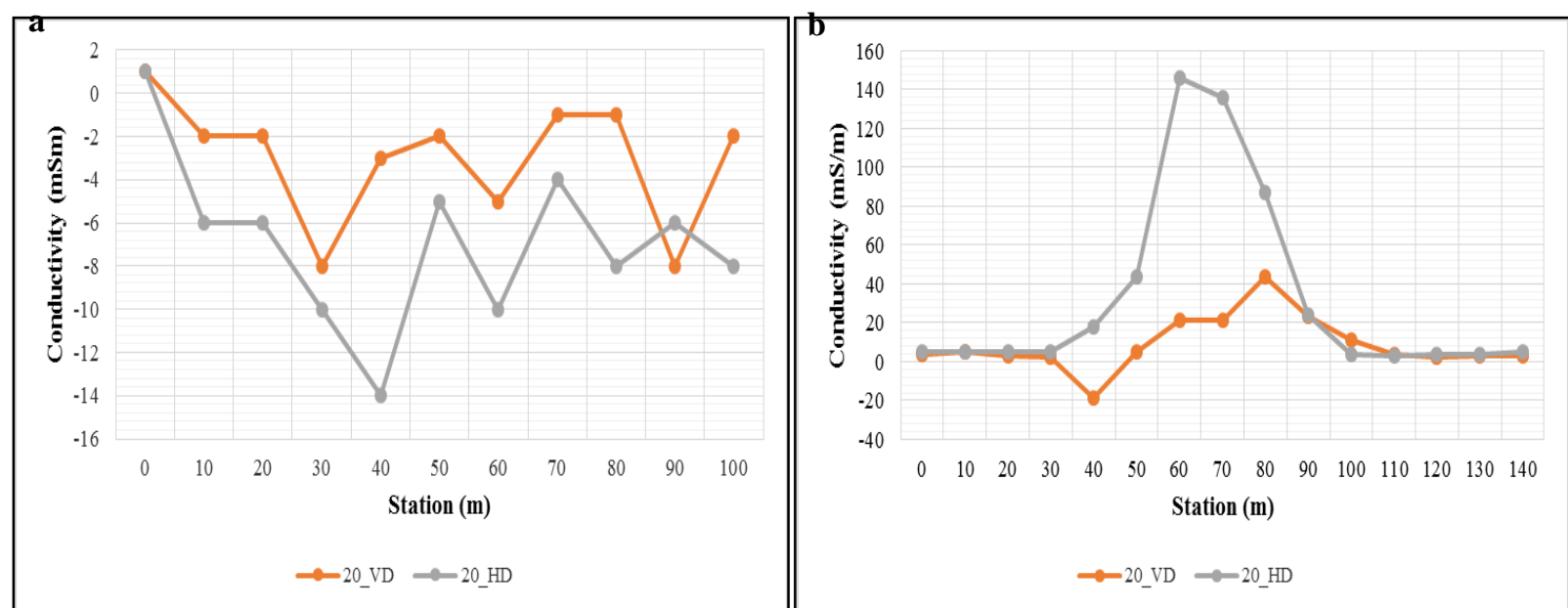

Fig. 8 EM Terrain Conductivity Measurement showing (a) Negative Conductivity and (b) High Conductivity Measurement

Table 2 Conductivity Values related to Groundwater Occurrence in the Tarkwa Area

\begin{tabular}{|l|l|l|l|l|l|}
\hline \multirow{2}{*}{ Lithology } & \multicolumn{2}{|l|}{ Cross-over } & \multicolumn{2}{l|}{ Peak amplitude } & \multirow{2}{*}{ Remarks } \\
\cline { 2 - 5 } & HD & VD & HD & VD & \\
\cline { 2 - 5 } Huni Sandstone & $2-3$ & $2-3$ & $3-5$ & $3-8$ & $\begin{array}{l}\text { Moderate GW potential; the method should be used } \\
\text { with other geophysical method. }\end{array}$ \\
\hline Tarkwa Phyllite & $11-15$ & $12-22$ & $15-22$ & $15-22$ & $\begin{array}{l}\text { Good GW potential; the method can be used alone } \\
\text { for groundwater exploration }\end{array}$ \\
\hline Banket Series & $3-15$ & $5-19$ & $15-32$ & $13-22$ & Good GW potential; the method can be used alone \\
\hline $\begin{array}{l}\text { Kawere } \\
\text { Conglomerate }\end{array}$ & $2-8$ & $3-8$ & $5-9$ & $8-13$ & $\begin{array}{l}\text { Moderate GW potential; other geophysical methods } \\
\text { should be used to support EM results }\end{array}$ \\
\hline
\end{tabular}

All range of values are in $\mathrm{mS} / \mathrm{m}$; *Maximum depth of investigation; GW: Groundwater;

HD: Horizontal Dipole, VD: Vertical Dipole 


\section{Conclusion}

ERI results show that the best protocol to use in the Tarkwa area is the Schlumberger configuration because of its good signal strength. However, to probe at greater depth, the Dipole-dipole configuration is recommended because it probes deeper. The general resistivity distribution in the study area is $32-100000 \Omega \mathrm{m}$. Potential waterbearing zones in the Huni Sandstone occurs to a depth of $35 \mathrm{~m}$ with an average resistivity of 400 $\Omega \mathrm{m}, 60 \mathrm{~m}$ with resistivity of $600 \Omega \mathrm{m}$ in the Tarkwa Phyllite, $55 \mathrm{~m}$ with resistivity value of $600 \Omega \mathrm{m}$ in the Banket Series and $50 \mathrm{~m}$ with resistivity of 500 $\Omega \mathrm{m}$ in the Kawere Conglomerate.

The EM results also show the $20 \mathrm{HD}$ and VD modes are the best modes to be considered for interpretation of results. The crossover concept of interpretation is more effective than the peak amplitude concept.

Results from ERI and EM surveys also revealed that for a detailed geophysical studies to be effective more than one geophysical method should be applied so that where there are ambiguities in the use of one method, the other method can be used for confirmation.

Generally the ERI was more effective than the EM. The ERI is likely to give a potential $80 \%$ success rate as compared to $65 \%$ for the EM technique. Combining the two methods could give a possible success rate of $86 \%$ in the Tarkwa area.

\section{Acknowledgements}

The authors thank the University of Mines and Technology (UMaT), Tarkwa for funding this research. The authors will also like to acknowledge the crew that helped in the geophysical field data collection.

\section{References}

Anon. (2003), "Geophysical field protocols", Ghana Rural Water Project, World Vision International Report, 73pp.

Chegbeleh, L. P., Akudago, J. A., Nishigaki, M and Edusei, S. N. K. (2009), "Electromagnetic Geophysical Survey for Groundwater Exploration in the Voltaian of Northern Ghana", Journal of Environmental Hydrology, Vol. 17, Paper 19, pp. 1-16.

Dahlin T. (1996), "2D Resistivity Surveying for Environmental and Engineering Applications," First Break, Vol. 14, pp. 275-283.

Dahlin, T. and Zhou, B. (2004), "A Numerical Comparison of 2D Resistivity Imaging with 10 Electrode Arrays", Geophysical Prospecting, Vol. 52, pp. 379-398.
Ewusi, A. and Kuma, J. S. (2010), "Calibration of Shallow Borehole Drilling Sites Using the Electrical Resistivity Imaging Technique in the Granitoids of Central Region, Ghana", Natural Resources Research, Vol. 20, pp. 57-63.

Ewusi, A, Kuma, J. S. and Voigt, H. J. (2009), "Utility of the 2-D Multi-Electrode Resistivity Imaging Technique in Groundwater Exploration in the Voltaian Sedimentary Basin, Northern Ghana", Natural Resources Research, Vol. 18, pp. 267-275.

Ewusi, A. (2006), "Groundwater Exploration and Management using Geophysics: Northern Region of Ghana, Unpublished PhD Thesis, Bradenburg Technical University of Cottbus, Germany, $171 \mathrm{pp}$.

Fetter, C. W. (2001), Applied Hydrogeology, $4^{\text {th }}$ edition, Prentice-Hall, Inc., Upper Saddle River, New Jersey 07458, 589 pp.

Goldman, M. and Neubauer, F. M. (1994), "Groundwater exploration using integrated geophysical techniques", Surveys in Geophysics, Vol. 55, pp. 331-361.

Griffiths, D. H. and King, R. F. (1981), Applied Geophysics for Geologists and Engineers, $2^{\text {nd }}$ ed., Pergamon press plc, Oxford, England, 230 pp.

Gupta G., Patil, J. D. Maiti, S., Erram V. C., Pawar, N. J., Mahajan, S. H. and Suryawanshi, R. A. (2014), "Electrical Resistivity Imaging for Aquifer Mapping over Chikotra Basin, Kolhapur District, Maharashtra", Environ Earth Sci, DOI 10.1007/s12665-014-3971-5, 19 pp.

Hirdes, W. and Nunoo, B. (1994), "The Proterozoic Paleoplacers at Tarkwa Gold Mine, SW Ghana: Sedimentology, Mineralogy and Precise Age Dating of the Main Reef and West reef, and Bearing of the Investigations on Source Area Aspects", BGR Geol Jb, D100, Hannover, pp. 247-311.

Kortatsi, B. K. (2004), "The Impact of mining on Groundwater Quality in Tarkwa area”, Ghana, Water Research Institute, Council for Scientific and Industrial Research, Accra, Ghana, pp. 1119-1125.

Kuma, J. S. and Ewusi, A. (2009), "Water Resources Issues in Tarkwa Municipality, Southwest Ghana", Ghana Mining Journal, Vol. 11, pp. 37 - 46.

Kuma, J. S. (2002), "Environmental Hydrogeology of the Tarkwa Gold Mining District", Ghana, Unpublished PhD Thesis, Department of Civil Engineering, University of Newcastle, $296 \mathrm{pp}$.

Kuma, J. S. and Younger, P. L. (2001), "Pedological characteristics related to groundwater occurrence in the Tarkwa area, Ghana", Journal of African Earth Sciences, Vol. 33, No. 2, pp. 363-376.

Kuma, J. S. and Younger, P. L. (2000), "Conceptual Ground water Model and related 
environmental concerns in the Tarkwa area", Ghana Mining Journal, Vol. 6, pp. 42-52.

Loke, M. H. (1999), "Electrical imaging surveys for environmental and engineering studies", $A$ practical guide to 2-D and 3-D surveys, $61 \mathrm{pp}$.

Loke, M. H. and Baker, R. D. (1996), "Rapid inversion of apparent resistivity pseudosections by quasi-Newton method", Geophysical Prospecting, Vol. 44, pp. 131-152.

McNeill, J. D. (1980), "Electromagnetic Terrain Conductivity Measurement at Low Induction Numbers, Technical Note TN-6, Geonics Limited, Canada 15 pp.

Obosu, J. K. (2012), "Estimation of Underground Water in a section of the Abontiakoon Vertical Shaft at Goldfields Ghana Limited Tarkwa Mine", Unpublished MSc Thesis, University of Mines and Technology, Tarkwa, 144 pp.

Owen, R. J. Gwavara, O. and Gwaze, P. (2005), "Multi-electrode resistivity survey for groundwater exploration in the Harare greenstone belt, Zimbabwe", Hydrogeology Journal, Vol. 14, pp. 244-252.

Quaye, A. (2008), "Characterisation of Surface and Ground water within the concession of Goldfields Ghana Limited, Tarkwa-Mine", Unpublished MSc Thesis, University of Mines and Technology, Tarkwa, $101 \mathrm{pp}$.

Tsiboah, T. (2002), "2D Resistivity and TimeDomain EM in aquifer mapping: a case study, north of Lake Naivasha, Kenya", Unpublished MSc Thesis, International Institute for Geoinformation Science and Earth Observation, 110 pp.

Whitelaw, O. A. L., (1929), "Geological and Mining Features of the Tarkwa-Aboso Goldfields, Gold Coast Survey Memoir, No. 1, $27 \mathrm{pp}$.

Yakubu, I. (2008), "Local Area Deformation Monitoring: A Multi GPS Receiver Network System Approach - A Case Study", Unpublished MPhil Thesis, University of Mines and Technology, Tarkwa, 78 pp.

\section{Authors}

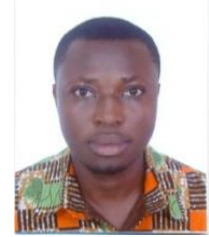

J. Seidu is an Assistant Lecturer at the University of Mines and Technology (UMaT), Tarkwa. He has an MPhil and BSc in Geological Engineering from UMaT. His research interest are Groundwater Studies, Geophysics and Water Resources Management.

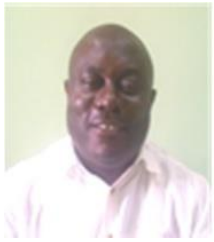

A. Ewusi is a Senior Lecturer at the University of Mines and Technology, Tarkwa, Ghana. He holds a PhD Hydrogeophysics and an MSc in Environmental Hydrogeology from the Brandenburg University of Technology, Germany. He obtained a BSc (Hons) Geological Engineering from the Kwame Nkrumah University of Science and Technology (KNUST), Kumasi, Ghana. His research interests are in groundwater management and geophysics.

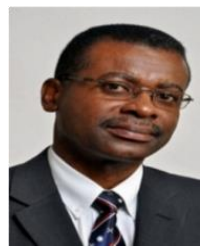

J. S. Y. Kuma is a Professor in Environmental Hydrogeology and Geophysics at the University of Mines and Technology (UMaT), Tarkwa. He was awarded a BSc (Hons) in Geology and Physics at the University of Ghana, Legon. He received the Pg Dip and MSc degrees in Geophysics at Delft, The Netherlands. He holds a $\mathrm{PhD}$ in Water Resources Engineering from the University of Newcastle upon Tyne, England. He is a member of Ghana Institution of Engineers, International Association of Hydrogeologists, and Ghana Institution of Geoscientists and also a fellow of African Scientific Institute. He is currently actively involved in mine water hydrogeological research and water management issues. 